\title{
N-HEXANE NEUROPATHY WITH VERTIGO AND COLD ALLODYNIA IN A SILK SCREEN PRINTER: A CASE STUDY
}

\section{SUNIL PRADHAN and RUCHIKA TANDON}

Sanjay Gandhi Post Graduate Institute of Medical Sciences, Lucknow, India

Department of Neurology

\begin{abstract}
$\mathrm{N}$-hexane neuropathy is an occupational disease caused by exposure to n-hexane, which is used as a solvent in silk screen printing. Here, we describe a 35-year-old man, a silk screen printer by profession, who presented with dizziness, distal swelling of both lower limbs for 10 months and tingling and burning sensation in both feet for 9.5 months along with cold allodynia. The patient had normal results of a motor and sensory system examination, apart from an impaired temperature sense. Nerve conduction tests showed a conduction block in bilateral common peroneal nerves and absence of conduction in bilateral sural nerves. These symptoms resolved when further exposure to n-hexane was ceased but cold allodynia remained. Thus, cold allodynia and impaired temperature sense can be a manifestation of n-hexane neuropathy. Hence, abnormalities on nerve conduction studies can be detected in n-hexane neuropathy patients, even before clinical examination detects any such abnormalities. In the case of the patients presenting with sensory motor neuropathy, history of occupational exposure to n-hexane becomes important, as the sooner the disease is detected, the better the chances of recovery.
\end{abstract}

Key words:

N-hexane, Occupational Diseases, Silk screen printing, Solvents

\section{INTRODUCTION}

Occupational neurotoxic diseases have become increasingly common in developing countries, mainly due to industrialization. The most common neurotoxic diseases include: organophosphate poisoning, heavy metal intoxication and organic solvent poisoning [1]. The nervous system is particularly vulnerable to toxic agents because of its high metabolic rate. Neurological manifestations may be transient or permanent, and may have a wide range of clinical manifestations [2].

Chronic exposure to n-hexane is one of the better known causes of peripheral neuropathy. This type of neuropathy is commonly seen among individuals employed in shoe and bag factories with inadequate ventilation [3,4]. It has been also observed in glue-sniffing addicts [5]. Silk printing is another, less known, occupational exposure to nhexane [6]. Exposure to n-hexane may occur via inhalation of toxic vapors or via percutaneous route $[3,4,6]$. Early recognition of manifestations of n-hexane toxicity is essential to protect workers of such professions from developing adverse effects of n-hexane.

\section{CASE REPORT}

A 35-year-old man presented to the outpatient department of Sanjay Gandhi Post Graduate Institute of Medical

Received: May 16, 2014. Accepted: January 24, 2015.

Corresponding author: S. Pradhan, Sanjay Gandhi Post Graduate Institute of Medical Sciences, Department of Neurology, Rae Barelly Road, Lucknow, Uttar Pradesh, India 226014 (e-mail: drspradhan@ rediffmail.com). 
Sciences, Lucknow with a feeling of rotation of self, off and on, for 10 months. For 10 months, he was also experiencing distal swelling of both lower limbs, and for 9.5 months, tingling and burning sensation in both feet. Cold allodynia in the feet was also present for 9 months. There was no history of alcohol intake and he was not taking any prescription drugs.

The patient was a silk screen printer by profession and used to work bare handed and without wearing any mask or protective equipment. For the past 2 years, he had been working in a shop where greeting cards and banners were made, and flax printing was performed. The patient used to work in such conditions from 10 to $11 \mathrm{~h}$ per day, all days of the week except for Thursdays. He used to take a half-an-hour lunch break in between. All together there were 15 workers in this shop, but 3 persons, including this patient, were involved in silk screen printing. The other screen printers had been working for the past 1-2 years; one of them suffered from headaches and dizziness, while all of them complained of fatigue. None of them, however, had symptoms of neuropathy. All the 3 workers took part in the entire screen printing process, including cleaning of the excess dye with solvent fluid containing n-hexane.

The excess dye was wiped off using a cloth held in bare hands and, after several uses, they used to throw that cloth away into a common garbage bin. However often the cloth was kept on the table used for printing or on the floor. The workers sometimes had lunch in the same room where printing was performed. Though the windows were kept open during the entire printing process and exhaust fan was used off and on, there was no device installed to reduce environmental exposure to n-hexane vapors. Annually, there was a consumption of 20-25 1 of the solvent fluid, containing n-hexane. There was no history of diabetes or of exposure to chemotherapeutic agents.

On examination, the patient was conscious and time, place and person oriented. He had all the cranial nerves intact and in all 4 limbs had a normal muscle bulk, tone and power. Also his reflexes and sensations were intact in all 4 limbs, apart from an impaired temperature sense in both feet. His hematological parameters, fasting and postprandial blood sugar levels, liver and renal function tests, and thyroid function tests were normal.

The workers were not monitored biologically and they only knew that the chemicals used were toxic, and that the hands should be washed before having anything to eat.

The patient's nerve conduction tests showed a conduction block in bilateral common peroneal nerves and bilateral sural nerves showed absence of conduction. The patient was given symptomatic treatment in a form of pregabalin and nerve vitamins. The patient changed his job, and after around 6 months, the symptoms of tingling and numbness of the lower limbs and feeling of rotation disappeared, even after stopping pregabalin. Nevertheless, cold allodynia in the lower limbs persisted.

\section{DISCUSSION}

Various neurological manifestations, including neuropathy, may result from occupational exposure to $n$-hexane. Previous studies have shown that the most common symptoms preceding n-hexane neuropathy are: headache, anorexia, dizziness and weight loss [7]. Our patient also presented with a feeling of rotation of self, off and on.

The previous studies have shown that numbness and weakness of the lower extremities are the initial symptoms that ascend to the upper extremities. Sensory loss and dyskinesia begin from the distant parts of the limbs. Patients have reduction or disappearance of tendon reflexes, weakness and muscle atrophy in the limbs [7,8]. Occupational n-hexane exposure has been shown to cause subacute neuropathy and the duration of exposure is important for neurological outcome. The prognosis of n-hexane induced neuropathy is well if correct diagnosis is made and further exposure is ceased $[8,9]$.

Additionally, the recent studies have revealed that expression of neuropathy is dependent upon the daily rate of 
toxicant exposure, and suggested that the toxic axonopathy classification might be based on epiphenomena related to dose-rate [10]. Our patient suffered from distal swelling of both lower limbs and tingling and burning sensation in both feet, initially with a feeling of cold in both feet. In our patient, the reflexes were preserved, probably due to the short duration of the disease.

According to the previous studies, significant decrements in sensory action potential (SAP) amplitudes for the median and sural nerves have been shown to be indicators for early detection of n-hexane-induced peripheral neuropathy in asymptomatic workers with exposure to n-hexane $[4,11]$. Also a decrease in motor and sensory conduction velocities in people exposed to n-hexane has been shown in the previous studies [12]. Additionally, in n-hexane neuropathy, decreased motor nerve conduction velocity with focal conduction block followed by dramatically diminished compound muscle action potentials (CMAPs) has been shown [13].

A study on silk screen printers has shown that $92 \%$ of the patients had sensory-motor neuropathy, while pure sensory neuropathy was seen in 2 of them. Sensory conduction was affected almost equally in the upper as well as lower limbs, while motor conduction was affected more in the lower limbs when compared to the upper ones. Sensory conduction was not recordable in both the upper and lower limbs in $72 \%$ of the patients. Motor conduction studies have revealed an asymmetric and patchy involvement. Conduction blocks were seen. On needle electromyography (EMG), the features of denervation have been seen in all the patients in a previous study [6,14-16]. Also in our patient there were features suggestive of sensorymotor neuropathy with a conduction block in bilateral common peroneal nerves and absence of conduction in bilateral sural nerves.

The previous studies have shown that the electrophysiological abnormalities in severe n-hexane neuropathy patients can revert after treatment, and the clinical prognosis is good [17]. Our patient improved symptomatically within 6 months of the treatment and became asymptomatic.

The presence of intermediate filaments in Schwann cells, as seen in the ultrastructural examination, in previous studies, together with the electrophysiological findings showing an early decrease of sensory and motor nerve conduction velocities, suggest existence of a primary myelinic disorder associated with axonal damage as a cause of n-hexane neuropathy [13].

Our study supports this hypothesis as on electrophysiological studies, sensory and motor demyelination with probably associated axonal damage was also seen in our patient. A study on the humoral immune responses to serum myelin proteins in mediating the occurrence and development of n-hexane peripheral neuropathy shows that this disease involves immunological mechanisms. Zero protein and their antibodies in serum have been proposed as a short-term effect biomarker of n-hexane exposure and peripheral nerve neuropathy [18].

Genetic factors influence an individual response to n-hexane [19]. This could explain why the other coworkers of our patient did not suffer from neuropathy. Cold allodynia can be an early symptom of n-hexane neuropathy. However, this patient also had an impaired temperature sense in both feet, which has not been shown in the previous studies. Also intact reflexes and sensation in all 4 limbs as seen in this patient have not been shown in the previous studies. It was probably due to a very early stage of the disease in this patient.

Hence, n-hexane neuropathy can initially present only with some sensory symptoms in the absence of sensory signs or motor abnormalities. In such patients neurodiagnostic studies alone may reveal abnormalities. The sooner the disease is suspected, the better the chances of recovery - just like in the case of our patient. Therefore, history of occupational exposure to n-hexane becomes important in the patients presenting with sensory motor neuropathy. 
Absence of environmental data remains a limitation of this study. Since it is an occupational disease, proper measures must be taken by employers in order to protect employees from exposure, for example, by the use of gloves and masks. Encouraging employees to proper hand washing practices and proper disposal of toxic waste is also important.

\section{REFERENCES}

1. Liu CH, Huang CY, Huang CC. Occupational neurotoxic diseases in Taiwan. Saf Health Work. 2012;3(4):257-67, http:// dx.doi.org/10.5491/SHAW.2012.3.4.257.

2. Magnavita N. A cluster of neurological signs and symptoms in soil fumigators. J Occup Health. 2009;51(2):159-63, http:/ dx.doi.org/10.1539/joh.N8007.

3. Sendur OF, Turan Y, Bal S, Gurgan A. Toxic neuropathy due to n-hexane: Report of three cases. Inhal Toxicol. 2009;21(3):210-4.

4. Neghab M, Soleimani E, Khamoushian K. Electrophysiological studies of shoemakers exposed to sub-TLV levels of n-hexane. J Occup Health. 2012;54(5):376-82, http://dx.doi. org/10.1539/joh.12-0029-FS.

5. Towfighi J, Gonatas NK, Pleasure D, Cooper HS, McCree L. Glue sniffer's neuropathy. Neurology. 1976;26(3):238-43, http://dx.doi.org/10.1212/WNL.26.3.238.

6. Chang CM, Yu CW, Fong KY, Leung SY, Tsin TW, Yu YL, et al. N-hexane neuropathy in offset printers. J Neurol Neurosurg Psychiatry. 1993;56(5):538-42, http://dx.doi. org/10.1136/jnnp.56.5.538.

7. Kuang S, Huang H, Liu H, Chen J, Kong L, Chen B. [A clinical analysis of 102 cases of chronic n-hexane intoxication]. Zhonghua Nei Ke Za Zhi. 2001;40(5):329-31. Chinese.

8. Misirli H, Domaç FM, Somay G, Araal O, Ozer B, Adigüzel T. N-hexane induced polyneuropathy: A clinical and electrophysiological follow up. Electromyogr Clin Neurophysiol. 2008;48(2):103-8.

9. Wang C, Chen S, Wang Z. Electrophysiological follow-up of patients with chronic peripheral neuropathy induced by occupational intoxication with n-hexane. Cell Biochem
Biophys. 2014;70(1):579-85, http://dx.doi.org/10.1007/s12013014-9959-7.

10. LoPachin RM, Gavin T. Toxic neuropathies: Mechanistic insights based on a chemical perspective. Neurosci Lett. 2015 Jun 2;596:78-83, http://dx.doi.org/10.1016/j.neulet.2014.08.054.

11. Pastore C, Marhuenda D, Marti J, Cardona A. Early diagnosis of n-hexane-caused neuropathy. Muscle Nerve. 1994;17(9):981-6, http://dx.doi.org/10.1002/mus.88 0170904.

12. Kutlu G, Gomceli YB, Sonmez T, Inan LE. Peripheral neuropathy and visual evoked potential changes in workers exposed to n-hexane. J Clin Neurosci. 2009;16(10):1296-9, http://dx.doi.org/10.1016/j.jocn.2008.12.021.

13. Jaumà S, Olivé M, Ferrer X, Montero J, Librán A, MartínezMatos JA. [Neuropathy by n-hexanes: A generalized disorder of the intermediate filaments]. Neurologia. 1998;13(9):41721. Spanish.

14. Puri V, Chaudhry N, Tatke M. N-hexane neuropathy in screen printers. Electromyogr Clin Neurophysiol. 2007;47 (3):145-52.

15. Pastore C, Izura V, Marhuenda D, Prieto MJ, Roel J, Cardona A. Partial conduction blocks in n-hexane neuropathy. Muscle Nerve. 2002;26(1):132-5, http://dx.doi.org/10.1002/ mus.10183.

16. Chang AP, England JD, Garcia CA, Sumner AJ. Focal conduction block in n-hexane polyneuropathy. Muscle Nerve. 1998;21(7):964-9, http://dx.doi.org/10.1002/\%28SICI \%291097-4598\%28199807\%2921:7\%3C964::AID-MUS 21\%3E3.0.CO;2-P.

17. Jiang $\mathrm{H}$, Chen LQ, Hu YY. [Electrophysiological study of 16 patients with severe N-hexane neuropathy]. Zhonghua Lao Dong Wei Sheng Zhi Ye Bing Za Zhi. 2005;23(5):351-4. Chinese.

18. Jia X, Liu Q, Zhang Y, Dai Y, Duan H, Bin P, et al. Myelin protein zero and its antibody in serum as biomarkers of n-hexane-induced peripheral neuropathy and neurotoxicity effects. Chin Med J (Engl). 2014;127(8):1536-40. 
19. Ghelli A, Porcelli AM, Zanna C, Vidoni S, Mattioli S, Barbieri A, et al. The background of mitochondrial DNA haplogroup $\mathrm{J}$ increases the sensitivity of Leber's hereditary optic neuropathy cells to 2,5-hexanedione toxicity. PLoS One. 2009;4(11):e7922, http://dx.doi.org/10.1371/journal. pone.0007922.

This work is available in Open Access model and licensed under a Creative Commons Attribution-NonCommercial 3.0 Poland License - http://creativecommons.org/ licenses/by-nc/3.0/pl/deed.en. 